\title{
Baseline characteristics and initial treatment decisions for patients with schizophrenia at risk of treatment nonadherence
}

This article was published in the following Dove Press journal:

Patient Preference and Adherence

10 August 2010

Number of times this article has been viewed

\author{
Katarina Kelin' \\ Alan JM Brnabic ${ }^{2}$ \\ Richard Newton ${ }^{3}$ \\ Raúl I Escamilla ${ }^{4}$ \\ Liang-Jen Chuo ${ }^{5}$ \\ Malina Simu ${ }^{6}$ \\ Wenyu $\mathrm{Ye}^{2}$ \\ William Montgomery' \\ Jamie Karagianis ${ }^{7}$ \\ Haya Ascher-Svanum ${ }^{8}$ \\ 'Eli Lilly Australia Pty Ltd, West Ryde, \\ NSW, Australia; ${ }^{2}$ Intercontinental \\ Information Sciences, Eli Lilly \\ Australia Pty Ltd, Macquarie Park, \\ NSW, Australia; ${ }^{3}$ Peninsula Health \\ Psychiatric Services, Frankston \\ Hospital, Frankston, VIC, Australia \\ (current affiliation: Department \\ of Psychiatry, Austin Hospital, \\ Heidelberg, VIC, Australia); \\ ${ }^{4}$ Schizophrenia Clinic, National \\ Institute of Psychiatry, Mexico \\ City, México D.F; ${ }^{5}$ Department of \\ Psychiatry, Taichung Veterans General \\ Hospital, Taichung, Taiwan; ${ }^{6}$ St Stelian \\ Hospital, Bucharest, Romania; ${ }^{7}$ Eli Lilly \\ Canada Inc., Toronto, ON, Canada; \\ ${ }^{8}$ US Outcomes Research, Lilly \\ Research Laboratories, Eli Lilly and \\ Company, Indianapolis, IN, USA
}

Correspondence: Katarina Kelin Eli Lilly Australia Pty Ltd, 112 Wharf Road, West Ryde, NSW, 2 I I 4, Australia

$\mathrm{Tel}+6 \mathrm{I} 29325-4672$

Fax +6I 29325-4699

Email kelin_katarina@lilly.com

\begin{abstract}
In this year-long, prospective observational study, sociodemographic, clinical, and functional characteristics were assessed in outpatients with schizophrenia from Australia, Mexico, Romania, and Taiwan who were switched from their primary oral antipsychotic to another oral or depot antipsychotic at study entry because of physician-perceived nonadherence risks. Patients $(\mathrm{N}=406)$ rated their quality of life and functioning level as low. Few patients $(10.6 \%, 43 / 406)$ were switched to depot antipsychotics, with country-specific differences $(P<0.001)$. Although illness severity was similar between subgroups, the depot switch subgroup had: a documented history of nonadherence (32.6\% versus oral: $4.7 \%)$; recent alcohol $(48.8 \%$ versus $23.2 \% ; P<0.001)$ or illicit drug use $(16.3 \%$ versus $5.0 \% ; P=0.010)$; recent depot antipsychotic $(20.7 \%$ versus $7.5 \% ; P=0.030)$ and mood stabilizer use $(51.7 \%$ versus $26.3 \%$; $P=0.008)$; poorer attitudes towards medication $(P=0.004)$; and poorer illness awareness $(P=0.041)$. Findings indicate that even when a risk of nonadherence has been identified, few patients with schizophrenia receive depot antipsychotics, despite being prime candidates for depot therapy. Findings suggest physicians may select depot therapy based on previous nonadherence, substance use, recent depot antipsychotic and mood stabilizer use, poor attitudes towards medications, and poor illness awareness.
\end{abstract}

Keywords: antipsychotic drugs, schizophrenia, depot antipsychotic, nonadherence

Nonadherence with antipsychotic medication is a common problem for patients with schizophrenia and is a reliable predictor for relapse, hospitalization, and poor long-term functional outcomes. ${ }^{1-3}$ How the physician responds to and identifies effective treatment strategies for these patients can be challenging, as medication nonadherence is a dynamic rather than a static situation. Patients may discontinue their antipsychotic medication for various and complex reasons including insufficient efficacy or concerns around tolerability of the medication. ${ }^{1}$ In addition, patients with a history of medication nonadherence, or who have poor insight into having a mental illness or a negative attitude to their medication may be at increased risk of nonadherence. ${ }^{4,5}$

Most treatment guidelines recommend that depot antipsychotics be considered as a treatment option for nonadherent patients who are at risk of relapse or who relapse frequently. ${ }^{6-10}$ Despite these recommendations, the use of depot antipsychotics varies among countries and regions, ${ }^{11-13}$ and in some countries, such as the United States, few nonadherent patients appear to be treated with depot antipsychotics. ${ }^{4,14}$

Several retrospective claims database studies and retrospective analyses of prospective observational studies involved examinations of the sociodemographic, clinical, and functional characteristics of patients switched to, or treated with, depot 
antipsychotics. ${ }^{4,15-18}$ Factors identified in these studies that may influence whether patients are switched to depot or oral antipsychotics include gender, age, alcohol and/or illicit drug use, treatment pattern, and clinical profile. These retrospective analyses are useful for identifying factors that may influence treatment decisions in routine clinical practice. However, prospective, naturalistic studies of nonadherent patients with schizophrenia are needed to confirm the findings of these retrospective analyses.

In this one-year, prospective, noninterventional, observational study, physicians in Australia, Mexico, Romania, and Taiwan treating outpatients with schizophrenia assessed their patients' risk of nonadherence. Patients who were considered to be at risk of nonadherence and who were switched from their primary oral antipsychotic medication to another oral or a depot antipsychotic at study entry, at their physician's discretion, were included in this study. At study entry, the patient's sociodemographics, psychiatric illness and treatment history, previous resource utilization, and patient-reported medication adherence were collected, and the patient's illness severity, attitude to their medication(s), insight into their illness, and quality of life were assessed.

The aim of this report was to describe the sociodemographic, clinical, and functional characteristics of patients at risk of nonadherence, and to compare these characteristics of patients who were switched to a depot antipsychotic with patients who were switched to another oral antipsychotic at study entry.

\section{Methods Study design}

This was a one-year, prospective, multicenter, noninterventional, observational study of outpatients with schizophrenia who required a change in their primary antipsychotic treatment because of a physician-perceived risk of nonadherence. The primary objective of this study was to establish the time to all-cause treatment discontinuation of the antipsychotic initiated at study entry, which will be reported in a subsequent report; however, this report is focused on the patients' sociodemographic, clinical, and functional characteristics at study entry. The study was conducted from April 2007 to July 2009 in 31 clinical practice sites located in Australia (10), Mexico (3), Romania (14), and Taiwan (4).

All patients provided voluntary, written informed consent for the use of their personal health information collected in the study. The study was conducted in accordance with the Declaration of Helsinki and the applicable laws and regulations of the study countries and regions, and was confirmed to be noninterventional by ethical review boards in each study country and region.

\section{Study population}

Patients included in this study were male or female outpatients (day hospitalization allowed) who met the DSM-IV or DSM-IV TR diagnostic criteria for schizophrenia. ${ }^{19}$ Patients were aged between 18 and 65 years and in the 24 months before study entry they had had at least two episodes that required hospitalization, an increase in the level of care (ie, the addition of, or change to, a day hospital program, outpatient crisis management, or short-term psychiatric treatment in an emergency room), or a change in medication regimen (ie, an increase in medication dose, or the addition of, or switch to, another medication). In addition, patients included in this study required a switch/change to their primary antipsychotic medication (defined as a switch to another antipsychotic of the same or different class, a change in antipsychotic formulation, or the addition of another antipsychotic at a therapeutic dose) because of a physicianperceived risk of nonadherence. Physicians assessed each patient's risk of nonadherence based on their best clinical judgment, and were asked to select a reason for the patient's risk of nonadherence from the following: lack of insight, a negative drug attitude, a documented history of medication nonadherence, an inadequate response to the primary antipsychotic medication, or intolerance to the primary antipsychotic medication.

Patients were excluded if they were considered by the physician to be treatment-resistant, or were receiving clozapine because of treatment resistance at study screening; were pregnant or nursing; or had an acute, serious, or unstable medical condition.

\section{Treatment}

Patients enrolled in the study were not randomized to treatment groups and there was no treatment blinding. The treating physician determined all aspects of treatment and care of the patient in keeping with their best clinical judgment; treatment decisions were solely at the discretion of the physician and the patient, and treatment was prescribed according to the usual standard of care. Patients perceived to be at risk of nonadherence were switched from their primary oral antipsychotic medication to another oral antipsychotic medication, or to a depot antipsychotic medication, up to 90 days before study entry (Day 0 ). 


\section{Patient assessment}

Patients were observed for 12 months following enrolment, and were assessed at study entry (Day 0), Month 3, Month 12, and if they relapsed or withdrew from the study. Variables collected at study entry were the patient's sociodemographics, psychiatric illness and treatment history, resource utilization, patient-reported medication adherence, illness severity, attitude to their medication(s), insight into their illness, and quality of life. Illness severity and the patient's insight into their illness were assessed by the physician using the Clinical Global Impressions of Severity (CGI-S) scale, ${ }^{20}$ and the abbreviated version of the Scale to Assess Unawareness of Mental Disorder (SUMD-A). ${ }^{21}$ Patient's attitude to their medication(s) was assessed using the self-report, 10-item Drug Attitude Inventory (DAI-10) questionnaire. ${ }^{22}$ Quality of life was assessed using the self-reported European Quality of Life instrument (EQ-5D), ${ }^{23}$ and health-related quality of life was assessed using the patient-rated, 12-item Short Form health survey (SF-12). ${ }^{24}$ United Kingdom (UK) adult populationbased preferences for the EQ-5D health states were used to calculate the EQ-5D utility score, ${ }^{25}$ as country-level norms were not available for the participating countries.

\section{Statistical analysis}

All patients who provided consent to release information and who fulfilled the study entry criteria were included in the analyses. To provide a more accurate representation of patient's clinical and functional illness profile at study entry, analyses of the CGI-S, DAI-10, EQ-5D, and SUMD-A scores excluded patients who switched treatment more than 7 days before their first study visit and analyses of SF-12 scores excluded patients who switched treatment more than 28 days before their first study visit.

Patient data were analyzed for all patients, and for patients who switched to a depot (depot switch subgroup) or oral (oral switch subgroup) antipsychotic at the time point closest to study entry. All data are summarized using means and standard deviations for continuous variables and counts and percentages for categorical variables. Comparisons between the depot and oral switch subgroups were analyzed using Student's $t$ test or the Wilcoxon rank sum test for continuous variables and Fisher's exact test (with or without Monte Carlo simulation) for categorical variables. For the comparisons of the CGI-S, DAI-10, EQ-5D, SF-12, and SUMD-A scores, the standardized mean difference effect size (Cohen's $d$ ) was also calculated. ${ }^{26}$ Statistical significance was set at $P<0.05$ (two-sided test). All statistical analyses were carried out using SAS $^{\circledR}$ Version 9.1.3 (SAS, Cary, N.C.).

\section{Results}

\section{Patient disposition}

Of the patients with schizophrenia $(\mathrm{N}=7462)$ reviewed by the study physicians, $15.9 \%$ (1187/7462) were considered to be at risk of nonadherence (Figure 1). The proportion of nonadherent patients was higher in Taiwan $(21.5 \%$, 236/1100) and Australia (19.6\%, 250/1275) than in Mexico $(13.1 \%, 175 / 1335)$ and Romania $(14.0 \%, 526 / 3752)$. Of these patients, 706 were eligible for study entry; however, 38\% (268/706) refused to participate.

A total of 406 patients at risk of nonadherence were switched from their primary oral antipsychotic medication to a depot or other oral antipsychotic within 90 days of study entry (Day 0) (Figure 1). Of these patients, 84.5\% (343/406) had switched antipsychotics within 7 days of study entry. Most patients $(n=363)$ were switched from their primary oral antipsychotic medication to another oral antipsychotic (Table 1); 53.7\% (218/406) were switched

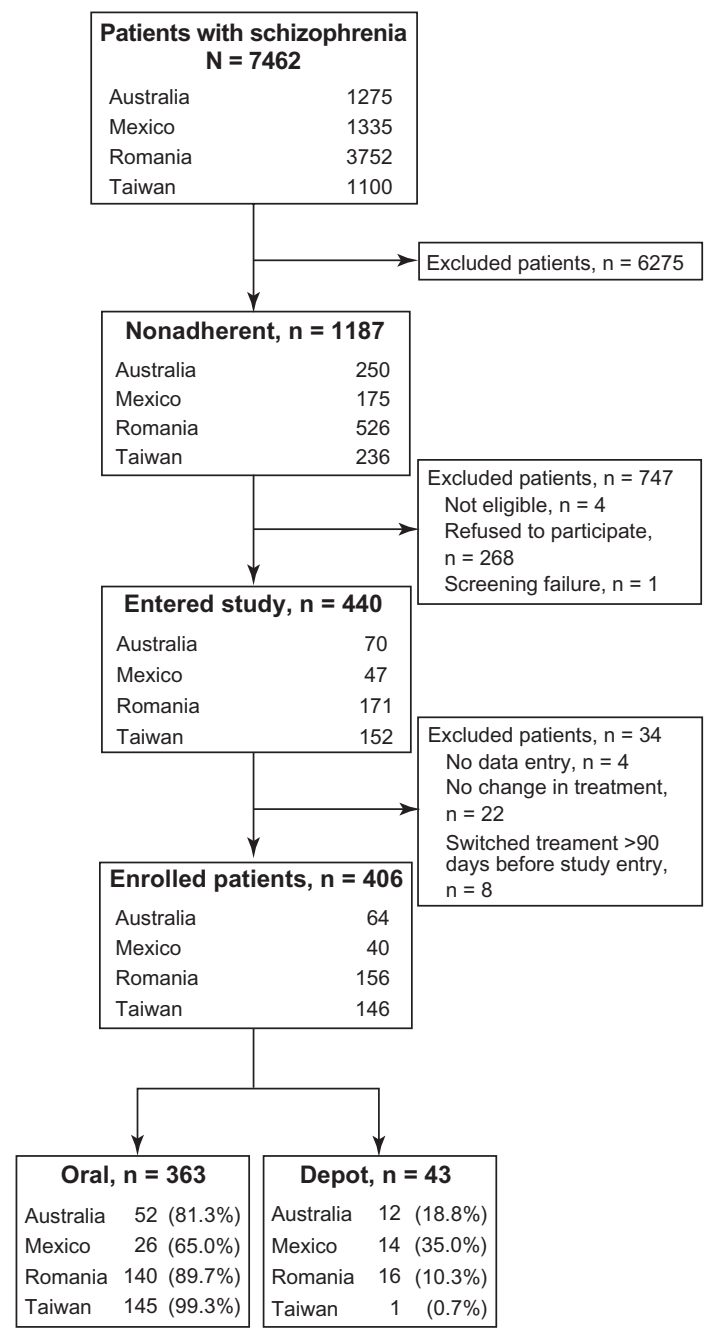

Figure I Patient disposition. 
Table I Antipsychotic switch pattern in the overall patient group $(\mathrm{N}=406)$

\begin{tabular}{|c|c|c|c|}
\hline \multicolumn{3}{|l|}{ Antipsychotic } & \multirow[t]{2}{*}{ n (\%) } \\
\hline Before switch ${ }^{a}$ & & After switch ${ }^{b}$ & \\
\hline Oral & $\rightarrow$ & Depot & $40(9.9)$ \\
\hline First-generation & & First-generation & $8(2.0)$ \\
\hline First-generation & & Second-generation & $2(0.5)$ \\
\hline Second-generation & & First-generation & $12(3.0)$ \\
\hline Second-generation & & Second-generation & $18(4.4)$ \\
\hline Oral & $\rightarrow$ & Depot + Oral & $3(0.7)$ \\
\hline Second-generation & & $\begin{array}{l}\text { Second-generation + } \\
\text { second-generation }\end{array}$ & $2(0.5)$ \\
\hline Second-generation & & $\begin{array}{l}\text { First-generation + } \\
\text { first-generation }\end{array}$ & I $(0.2)$ \\
\hline Oral & $\rightarrow$ & Oral & $36 I(88.9)$ \\
\hline First-generation & & First-generation & $24(5.9)$ \\
\hline First-generation & & Second-generation & $105(25.9)$ \\
\hline Second-generation & & First-generation & $14(3.4)$ \\
\hline Second-generation & & Second-generation & $218(53.7)$ \\
\hline Oral & $\rightarrow$ & Oral + Oral & I (0.2) \\
\hline Second-generation & & $\begin{array}{l}\text { Second-generation + } \\
\text { first-generation }\end{array}$ & I $(0.2)$ \\
\hline Oral + Oral & $\rightarrow$ & Oral & I (0.2) \\
\hline $\begin{array}{l}\text { First-generation + } \\
\text { first-generation }\end{array}$ & & Second-generation & $\mathrm{I}(0.2)$ \\
\hline
\end{tabular}

Notes: ${ }^{a}$ First-generation oral antipsychotics taken before switch: flupentixol, haloperidol, levomepromazine, perphenazine, pimozide,sulpiride, thioridazine, trifluoperazine, and zuclophenthixol. Second-generation oral antipsychotics taken before switch: amisulpride, aripiprazole, clotiapine, clozapine, olanzapine, paliperidone, quetiapine, risperidone, ziprasidone, and zotepine; 'Antipsychotic switch occurred up to 90 days before study entry.

from one second-generation oral antipsychotic to another second-generation oral antipsychotic. Few patients $(n=43)$ were switched to depot antipsychotic medication (Table 1). Although depot use was low in all countries and regions, Mexico had the highest proportion of patients who switched to depot (35\%) and Taiwan had the lowest proportion (0.7\%) (Figure 1). Country- and region-specific differences in the proportion of patients from each country and region who were switched to a depot or oral antipsychotic were observed $(P<0.001)$ (Table 2).

\section{Reasons for nonadherence}

More than half of the overall patient group was considered at risk of nonadherence by their physicians because of an inadequate response to their antipsychotic medication (Figure 2). Negative drug attitude and intolerance to drug were the next commonly cited reasons, followed by a documented history of medication nonadherence and lack of insight.

The proportion of each physician-perceived reason for nonadherence differed between the depot and oral switch subgroups $(P<0.001)$. Patients in the oral switch subgroup were predominantly considered at risk of nonadherence because of an inadequate response to their antipsychotic medication $(57.6 \%$, 209/363). Patients in the depot switch subgroup were predominantly considered at risk because of an inadequate response to their antipsychotic medication $(34.9 \%, 15 / 43)$ or a documented history of medication nonadherence $(32.6 \%, 14 / 43)$.

\section{Sociodemographic characteristics}

Overall, patients tended to be in their late 30 s and male (Table 2). Most patients had never married or were not in a relationship (59.6\%), lived with their family (82.0\%), were unemployed (43.4\%), and were not receiving an income $(54.6 \%)$ ). About $26 \%$ of patients had consumed alcohol and less than $10 \%$ had taken illicit drugs in the 6 months before study entry. Nearly $70 \%$ of patients considered themselves to be adherent (ie, reported they took all their medication or only missed taking their medication a couple of times).

In general, the sociodemographic characteristics of patients in the depot and oral switch subgroups were similar (Table 2). The subgroups were similar in terms of age, sex, body mass index, relationship status, living arrangements, or income status. Although a higher proportion of patients in the oral switch subgroup were employed (32.8\%) than in the depot switch subgroup (18.6\%), no significant differences in work status (employed, unemployed, or other) were observed between the subgroups. During the 6 months before study entry, a significantly higher proportion of patients in the depot switch subgroup consumed alcohol $(P<0.001)$ or used illicit drugs $(P=0.010)$ than patients in the oral switch subgroup. Up to $70 \%$ of patients in the oral switch subgroup and up to $60 \%$ of patients in the depot switch subgroup considered themselves to be adherent to their medication.

\section{Medical and treatment history}

In general, patients had their first episode of schizophrenia in their mid 20s, and had three episodes or exacerbations of schizophrenia and had been hospitalized once, on average, in the 24 months before study entry (Table 3). In the 12 months before study entry, patients had an average of 11 outpatient visits. In terms of treatment history, about $60 \%$ of patients had been treated with antipsychotics, or anxiolytics, sedatives, and hypnotics, $21 \%$ had been treated with antidepressants, and $29 \%$ had been treated with mood stabilizers during the 12 months before study entry. 
Table 2 Patient sociodemographic characteristics at study entry

\begin{tabular}{|c|c|c|c|c|}
\hline \multirow[t]{2}{*}{ Variable } & \multirow{2}{*}{$\begin{array}{l}\text { Overall } \\
(N=406)\end{array}$} & \multicolumn{3}{|c|}{ Switch subgroups } \\
\hline & & $\begin{array}{l}\text { Depot } \\
(n=43)\end{array}$ & $\begin{array}{l}\text { Oral } \\
(n=363)\end{array}$ & $P^{\mathrm{a}}$ \\
\hline Age (years), mean (SD) & $37.2(10.2)$ & $35.8(12.1)$ & $37.4(10.0)$ & 0.339 \\
\hline Male, $n(\%)$ & $230(56.7)$ & $28(65.1)$ & $202(55.6)$ & 0.258 \\
\hline BMI $\left(\mathrm{kg} / \mathrm{m}^{2}\right)^{\mathrm{b}}$, mean $(\mathrm{SD})$ & $26.1(5.56)$ & $27.3(6.08)$ & $26.0(5.48)$ & 0.139 \\
\hline \multicolumn{5}{|l|}{ Country/region, n (\%) } \\
\hline Australia & $64(15.8)$ & $12(27.9)$ & $52(14.3)$ & \multirow[t]{4}{*}{$<0.001$} \\
\hline Mexico & $40(9.9)$ & $14(32.6)$ & $26(7.2)$ & \\
\hline Romania & $156(38.4)$ & $16(37.2)$ & $140(38.6)$ & \\
\hline Taiwan & $146(36.0)$ & I (2.3) & 145 (39.9) & \\
\hline \multicolumn{5}{|l|}{ Relationship status, n (\%) } \\
\hline In relationship & $116(28.6)$ & $9(20.9)$ & $107(29.5)$ & \multirow[t]{3}{*}{0.485} \\
\hline Previous relationship & $48(1 \mathrm{I} .8)$ & $5(11.6)$ & $43(11.9)$ & \\
\hline No relationship & $242(59.6)$ & $29(67.4)$ & $213(58.7)$ & \\
\hline \multicolumn{5}{|l|}{ Living arrangements, n (\%) } \\
\hline Independent & $59(14.5)$ & $8(18.6)$ & $51(14.1)$ & \multirow[t]{3}{*}{0.496} \\
\hline Supervised & $14(3.5)$ & $2(4.65)$ & $12(3.3)$ & \\
\hline Family & $333(82.0)$ & $33(76.7)$ & $300(82.6)$ & \\
\hline \multicolumn{5}{|l|}{ Work status, n (\%) } \\
\hline Employed & $127(3 \mid .3)$ & $8(18.6)$ & $119(32.8)$ & \multirow[t]{3}{*}{0.151} \\
\hline Unemployed & $176(43.4)$ & $22(5 \mid .2)$ & $154(42.4)$ & \\
\hline Other & $103(25.4)$ & $13(30.2)$ & $90(24.8)$ & \\
\hline Receiving incomec, n (\%) & $183(45.4)$ & $17(40.5)$ & $166(46.0)$ & 0.518 \\
\hline Consumed alcohold $\mathrm{n}(\%)$ & $105(25.9)$ & $21(48.8)$ & $84(23.2)$ & $<0.001$ \\
\hline Used illicit drugs ${ }^{\mathrm{d}}, \mathrm{n}(\%)$ & $25(6.2)$ & $7(16.3)$ & $18(5.0)$ & 0.010 \\
\hline \multicolumn{5}{|l|}{ Patient-reported adherence to medication, n (\%) } \\
\hline Took all or almost all & $278(68.5)$ & $25(58.1)$ & $253(69.7)$ & \multirow[t]{3}{*}{0.207} \\
\hline Took at least half & $74(18.2)$ & $9(20.9)$ & $65(17.9)$ & \\
\hline Took less than half or stopped altogether & $54(13.3)$ & $9(20.9)$ & $45(12.4)$ & \\
\hline
\end{tabular}

Notes: ${ }^{a}$ Depot versus oral switch subgroup (Student's $t$ test for continuous variables or Fisher's exact test for categorical variables); ' $O$ verall, $\mathrm{N}=383$; depot, $\mathrm{n}=4 \mathrm{I}$; oral, $n=342$; 'Overall, $N=403$; depot, $n=42$; oral, $n=36$ I; 'In the 6 months before study entry; overall, $N=405 ;$ depot, $n=43 ;$ oral, $n=362$.

Abbreviations: BMI, body mass index; SD, standard deviation.

Although the illness history of both subgroups was somewhat similar, their treatment history before study entry differed (Table 3). Patients in the depot switch subgroup had their first episode of schizophrenia at a significantly younger age than patients in the oral switch subgroup $(P=0.006)$. In the 12 months before study entry, a significantly higher proportion of patients in the depot switch subgroup had been treated with depot antipsychotics $(P=0.030)$ than those in the oral switch subgroup. In terms of other psychiatric medications, a higher proportion of patients in the oral switch subgroup had been treated with anxiolytics, sedatives, and hypnotics $(P=0.002)$, whereas a higher proportion of patients in the depot switch subgroup had been treated with mood stabilizers $(P=0.008)$.

\section{Clinical and functional illness profile}

Overall, patients rated their attitude to their antipsychotic medication as slightly positive (DAI-10 score), and their quality of life and level of functioning as low (EQ-5D and
SF-12 scores) (Table 4). In addition, patients were considered to be moderately ill (CGI-S score), and were moderately aware of their illness (SUMD-A score).

Although there was no significant difference in illness severity (CGI-S score) between patients in the depot and oral switch subgroups, significant differences in the mean DAI-10, SUMD-A, and EQ-5D utility scores were observed between the subgroups (Table 4). Patients in the depot switch subgroup reported a significantly less positive attitude to their antipsychotic medication than patients in the oral switch subgroup (DAI-10 score; $P=0.004$ ). The effect size for this difference $(0.53)$ was medium. This less positive attitude was characterized by a diminished belief in the statement 'for me, the good things about my current medication outweigh the bad' $($ depot $=57.1 \%, 20 / 35$, versus oral $=77.5 \%$, $238 / 307 ; P=0.012$ ) and increased belief in the statements 'I take medications only when I am sick' (depot $=62.9 \%$, $22 / 35$, versus oral $=29.6 \%, 91 / 307 ; P<0.001$ ) and 'it is unnatural for my mind and body to be controlled by 


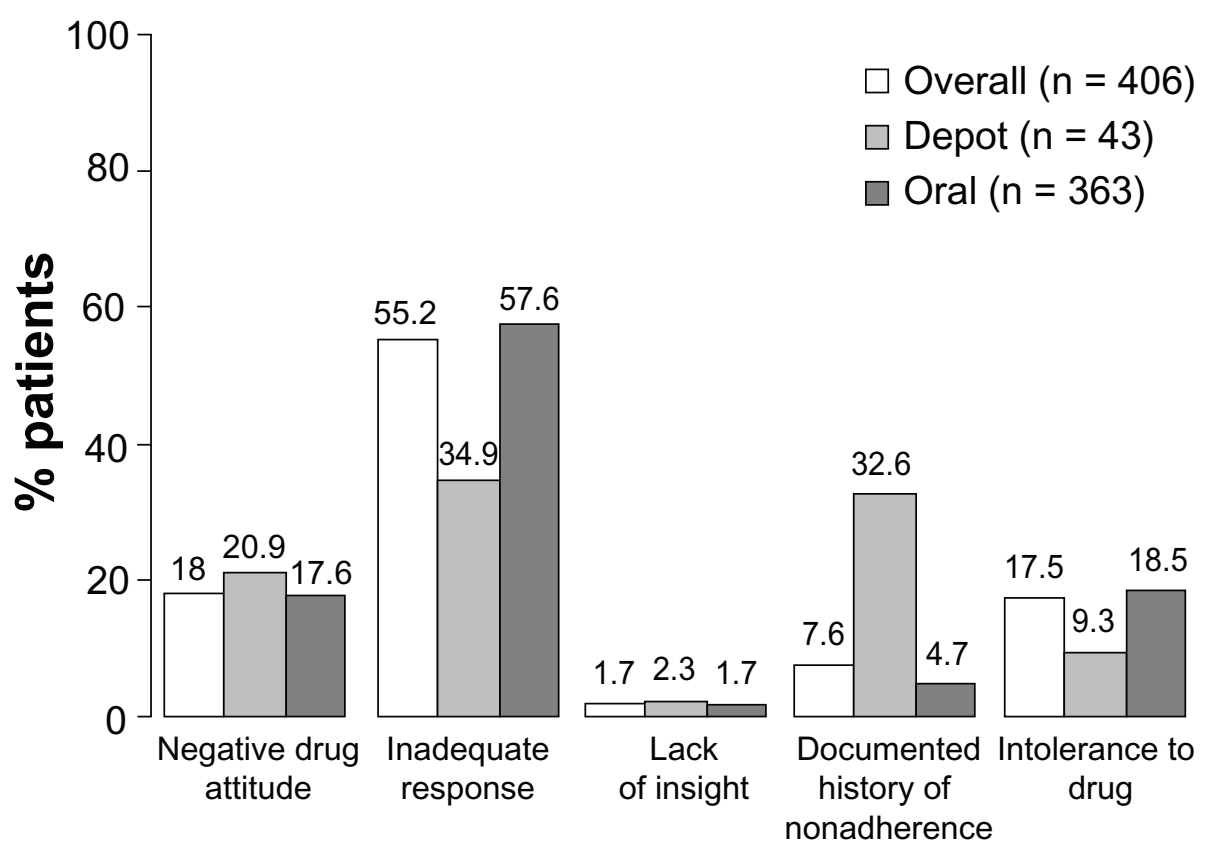

\section{Clinician-perceived reason}

Figure 2 Physician-perceived reasons for patients at risk of nonadherence at study entry. The proportion of each physician-perceived reason for nonadherence in each subgroup differed $(P<0.001)$ between the oral and depot switch subgroups (Fisher's exact test, Monte Carlo simulation).

medications' $($ depot $=77.1 \%, 27 / 35$, versus oral $=52.3 \%$, 161/308; $P=0.007)$.

Patients in the depot switch subgroup had a significantly poorer awareness of their illness than patients in the oral switch subgroup (SUMD-A score; $P=0.041$ ) and the effect size was small (0.38). This overall poorer awareness was characterized by significant differences in the SUMD-A variables 'awareness of mental disorder' $($ depot $=2.9 \pm 1.2$

Table 3 Patient medical and treatment history at study entry

\begin{tabular}{|c|c|c|c|c|}
\hline \multirow[t]{2}{*}{ Variable } & \multirow{2}{*}{$\begin{array}{l}\text { Overall } \\
(N=406)\end{array}$} & \multicolumn{3}{|c|}{ Switch subgroups } \\
\hline & & $\begin{array}{l}\text { Depot } \\
(n=43)\end{array}$ & $\begin{array}{l}\text { Oral } \\
(n=363)\end{array}$ & $P^{\mathrm{a}}$ \\
\hline Age of first episode (years), mean (SD) & $25.7(8.3)$ & $22.4(6.9)$ & $26.0(8.3)$ & 0.006 \\
\hline No. of previous episodes or exacerbations ${ }^{\mathrm{b}}$, median (range) & $2.0(1.9)$ & $2.0(0.3)$ & $2.0(0.3)$ & 0.911 \\
\hline No. of hospitalizations ${ }^{\mathrm{b}}$, mean $(\mathrm{SD})$ & I.I (I.5) & I.I (I.2) & $\mathrm{I} . \mathrm{I}(\mathrm{I} .5)$ & 0.910 \\
\hline No. of outpatient visits ${ }^{\mathrm{d}}$, mean (SD) & II.I (9.9) & $10.9(8.5)$ & II.I (10.1) & 0.920 \\
\hline \multicolumn{5}{|c|}{ Antipsychotic medication use in the 12 months before study entry, $\mathrm{n}(\%)$} \\
\hline Overall & $172(58.3)$ & $17(58.6)$ & $155(58.3)$ & 1.000 \\
\hline Oral & $153(51.9)$ & $15(5 \mid .7)$ & $138(51.9)$ & 1.000 \\
\hline First-generation & $77(26.1)$ & $4(13.8)$ & $73(27.4)$ & 0.125 \\
\hline Second-generation & $80(27.1)$ & $12(4 \mid .4)$ & $68(25.6)$ & 0.080 \\
\hline Depot & $26(8.8)$ & $6(20.7)$ & $20(7.5)$ & 0.030 \\
\hline First-generation & $15(5.1)$ & $5(17.2)$ & $10(3.8)$ & 0.010 \\
\hline Second-generation & $12(4.1)$ & $2(6.9)$ & $10(3.8)$ & 0.334 \\
\hline \multicolumn{5}{|c|}{ Other psychiatric medication use in the 12 months before study entry ${ }^{d}, \mathrm{n}(\%)$} \\
\hline Overall & $26 I(88.5)$ & $24(82.8)$ & $237(89.1)$ & 0.353 \\
\hline Antidepressants & $62(21.0)$ & $5(17.2)$ & $57(21.4)$ & 0.811 \\
\hline Anxiolytics, sedatives, hypnotics & $185(62.7)$ & $10(34.5)$ & $175(65.8)$ & 0.002 \\
\hline Mood stabilizers & $85(28.8)$ & $15(51.7)$ & $70(26.3)$ & 0.008 \\
\hline
\end{tabular}

Notes: 'Depot versus oral switch subgroup (Student's $t$ test for continuous variables or Fisher's exact test for categorical variables); 'اn the 24 months before study entry;

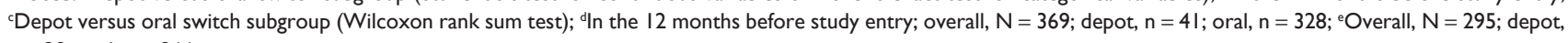
$\mathrm{n}=29$; oral, $\mathrm{n}=266$.

Abbreviation: SD, standard deviation. 
was assessed using the physicians' best clinical judgment rather than via a specific clinical scale or questionnaire, this assessment method may more closely reflect actual decisions required of physicians in routine clinical practice.

Patients in this study rated their quality of life and level of functioning as low, which was similar to the findings from the Worldwide-Schizophrenia Outpatient Health Outcomes (W-SOHO) study (median EQ-5D health state score $=50$; interquartile range $=30$ to 62 ), even though patients in that study were not selected according to nonadherence risk. ${ }^{13}$ Although a negative attitude or poor insight has been associated with nonadherence in patients with schizophrenia, ${ }^{5}$ patients in this study had a slightly positive attitude towards their medication and a moderate awareness of their illness. These differences may reflect the low proportion of patients (19.7\%) in this study who were considered at risk of nonadherence because of their attitude to medication and awareness of their illness.

The noninterventional and nonrandomized design of this study allowed physicians to choose the most appropriate antipsychotic treatment for their patients; however, few chose depot antipsychotics despite all enrolled patients being considered a nonadherence risk and, therefore, potential candidates for depot antipsychotics. This low rate is similar to the findings from a retrospective observational study in the United States, in which only $12.4 \%$ of patients considered to be nonadherent with oral antipsychotics were switched to depot antipsychotics. ${ }^{4}$ Given that few patients were switched to depot antipsychotics in this study, physician-perceived reasons for the risk of nonadherence, rather than the risk of nonadherence itself, may have guided the physician to switch patients to depot or oral antipsychotics.

Comparable with the baseline findings from the W-SOHO study, ${ }^{13}$ patients in this study switched antipsychotics at study entry mainly due to the physician-perceived reason of 'inadequate response', suggesting that physicians perceive a lack of drug efficacy as the predominant risk factor for nonadherence. Generally, a higher proportion of patients were switched to depot antipsychotics because of the physicianperceived reason 'documented history of nonadherence', a result supported by findings in other studies. ${ }^{11,32}$ These results suggest that development of an evaluation tool that further helps physicians to objectively assess a patient's risk of nonadherence and appropriateness for depot therapy may be beneficial.

Generalizing the study's findings to individual populations is challenging because of the distinct variability in antipsychotic prescribing practices across the study countries and regions. Only one of the 146 patients in Taiwan, compared with 14 of the 40 patients in Mexico, was switched to depot antipsychotics. This is not surprising, given the many differences among and within countries and regions in terms of treatment guidelines, treatment practices, availability of medications, and the dynamics of the patientdoctor relationship. ${ }^{33,34}$ In addition, antipsychotic prescribing practices may also be influenced by country-specific pharmaco-economic considerations, such as the affordability of medications and the cost of administering depot antipsychotics and treating potential adverse events. ${ }^{34,35}$ It is not known if cost was a deciding factor in treatment choice by patients or physicians in this study. The low use of depot antipsychotics in outpatients from Taiwan was surprising, particularly given that Taiwan had the highest proportion of patients considered to be at risk of nonadherence compared with the other study countries. However, findings from the W-SOHO study suggest that the use of depot antipsychotics is low (6.6\%) in the East Asian countries and regions (Korea, Malaysia and Taiwan) assessed. ${ }^{13}$ This low use of depot antipsychotics in outpatients may be explained by physician preference to prescribe depot antipsychotics to inpatients in some countries and regions (for example, it has been estimated that $10 \%$ to $20 \%$ of inpatients in Taiwan receive depot antipsychotics as part of their treatment regimen). ${ }^{12,36}$ However, more studies are needed to explore regional variations in antipsychotic prescription patterns and determine specific reasons for regional differences.

Although findings from previous retrospective analyses suggested that patients who were male and younger were preferentially switched to depot antipsychotics, ${ }^{4,15,16,18}$ this was not evident in our study. However, as our study was designed to assess the overall patient population, our ability to detect significant differences between subgroups and to draw qualitative conclusions for these variables may have been limited by the small sample size of the depot switch subgroup. Despite this limitation and in agreement with previous retrospective analyses, study results showed that a significantly higher proportion of patients in the depot switch subgroup had consumed alcohol or used illicit drugs in the 6 months before study entry. ${ }^{4,16}$ This is perhaps not surprising as substance abuse is a well established risk factor for poorer outcomes in patients with schizophrenia. ${ }^{37}$ In the Clinical Antipsychotic Trials of Intervention Effectiveness (CATIE) study, for example, illicit drug users were found to be less treatment-adherent and were more sick at baseline, had less illness course stability, and lived in more stressful social environments. ${ }^{37}$ Other sociodemographic variables 
associated with depot use, such as a history of involvement with the criminal justice system, ${ }^{4}$ were not assessed in this study.

Patients with a distinct previous treatment profile may have also been preferentially switched to depot antipsychotics. Patients treated with depot antipsychotics in the 12 months before study entry were more likely to be switched to depot antipsychotics than oral antipsychotics. Physicians are more likely to consider prescribing depot antipsychotics if their patient has had previous experience with depot. ${ }^{18,38}$ In addition, patient acceptance of depot antipsychotics increases with experience, ${ }^{38}$ and patients often prefer to continue taking their current antipsychotic formulation, particularly if it is an oral formulation. ${ }^{39}$ In this study, patients may have opted to continue taking oral antipsychotic formulations. However, it is not known what number of patients refused an offer of a depot antipsychotic from their physician. Previous research showed that up to $35 \%$ of patients have refused or would refuse treatment with depot antipsychotics. ${ }^{38,40}$

In addition, a significantly higher proportion of patients in the depot switch subgroup had been treated with mood stabilizers, and a significantly higher proportion of patients in the oral switch subgroup had been treated with anxiolytics, sedatives, and hypnotics (consistent with previously reported data) ${ }^{18}$ in the 12 months before study entry. Although the number of multiple comparisons done in this study may have increased the probability that some of the statistical differences observed may have arisen by chance alone, these results may reflect patient factors, eg, patients in the oral switch subgroup may be more engaged with the treatment team (and more likely to be prescribed anxiolytics, sedatives, and hypnotics). Although depot antipsychotics were not indicated for mood disorders at the time this study was conducted, patients in the depot switch subgroup may have been more aggressive and agitated (and therefore more likely to be prescribed mood stabilizers).

Interestingly, patients in the depot and oral switch subgroups had a similar level of illness severity at study entry. In a previous study, illness severity (eg, the number of previous hospitalizations) and a more severe treatment pattern (eg, recent switching or augmentation of oral antipsychotics) were identified as important drivers for depot use in nonadherent patients. ${ }^{4}$ Given this, the results from this study highlight the possibility that physician preference could influence treatment decisions. For example, physicians may believe that most of their patients are sufficiently adherent with oral antipsychotics, ${ }^{41}$ or that depot antipsychotics are less acceptable to patients and are stigmatizing. ${ }^{42,43}$ Patients in the depot switch subgroup had a significantly less positive attitude to their antipsychotic medication and an overall poorer awareness of their illness, which may align with a patient's risk of nonadherence. Poor adherence has been reported in patients that lack awareness of their illness, ${ }^{44}$ and in patients who believe in taking medicine only when they are ill, or that taking medicine can cause harm or is unnatural, ${ }^{45}$ beliefs shared by patients in the depot switch subgroup of this study.

This is the first prospective study in which the sociodemographic, clinical, and functional characteristics of patients considered to be at risk of nonadherence switched to either depot or oral antipsychotics were considered. The prospective observational design of this study is clinically relevant, as the study was conducted in naturalistic settings that provided an actual-practice view of the variables that may have influenced the switch to depot antipsychotics. Although all patients enrolled in this study were considered at risk of nonadherence, a key characteristic of patients switched to depot antipsychotics was a documented history of nonadherence. Other key characteristics included recent alcohol or illicit drug use, early age of illness onset, recent depot antipsychotic and mood stabilizer use, poor attitudes to medications, and a poor awareness of their illness.

Current findings are consistent with previous research, $4,16,18$ and show that the patient illness profile may influence a physician's choice of depot over oral antipsychotic therapy. Further research is needed, therefore, to better understand the assumptions that may drive physicians' choice of depot over oral antipsychotics for only a small proportion of those patients who are considered prime candidates for depot antipsychotic therapy.

\section{Acknowledgments}

This study was sponsored by Eli Lilly and Company. Eli Lilly was involved in the study design, data collection, data analysis, and preparation of the manuscript. In compliance with the Uniform Requirements for Manuscripts, established by the International Committee of Medical Journal Editors, the sponsor of this study did not impose any impediment, directly or indirectly, on the publication of the study's results.

The authors acknowledge statistical analysis assistance provided by George Zhao. The authors also acknowledge the independent medical writing assistance provided by ProScribe Medical Communications (www.proscribe.com.au), funded from an unrestricted financial grant from Eli Lilly 
Australia. ProScribe's services complied with international guidelines for Good Publication Practice.

\section{Contributors}

All authors participated in the interpretation of study results, and critically revised draft versions and approved the final version of the manuscript. AJM Brnabic, K Kelin, and W Montgomery participated in the design and conduct of the study. LJ Chuo, RI Escamilla, R Newton, and M Simu were investigators in the study. LJ Chuo, RI Escamilla, R Newton, and $\mathrm{W}$ Ye participated in data collection. AJM Brnabic and W Ye participated in the statistical analyses.

\section{Disclosure}

K Kelin, AJM Brnabic, J Karagianis, W Montgomery, W Ye, and $\mathrm{H}$ Ascher-Svanum are employees of Eli Lilly and Company. R Newton has received honoraria from AstraZeneca, Eli Lilly and Company, Janssen-Cilag Pty Limited, and Lundbeck Australia Pty Ltd. AJM Brnabic, J Karagianis, W Montgomery, and W Ye are shareholders in Eli Lilly and Company. LJ Chuo, RI Escamilla, and M Simu report no conflicts of interest in this work.

\section{References}

1. Lieberman JA, Stroup TS, McEvoy JP, et al. Effectiveness of antipsychotic drugs in patients with chronic schizophrenia. New Engl J Med. 2005;353:1209-1223.

2. McEvoy JP, Lieberman JA, Stroup TS, et al. Effectiveness of clozapine versus olanzapine, quetiapine, and risperidone in patients with chronic schizophrenia who did not respond to prior atypical antipsychotic treatment. Am J Psychiatry. 2006;163:600-610.

3. Stroup TS, Lieberman JA, McEvoy JP, et al. Effectiveness of olanzapine, quetiapine, risperidone, and ziprasidone in patients with chronic schizophrenia following discontinuation of a previous atypical antipsychotic. Am J Psychiatry. 2006;163:611-622.

4. Ascher-Svanum H, Peng X, Faries D, Montgomery W, Haddad PM. Treatment patterns and clinical characteristics prior to initiating depot typical antipsychotics for nonadherent schizophrenia patients. $B M C$ Psychiatry. 2009;9:46.

5. Lacro JP, Dunn LB, Dolder CR, Leckband SG, Jeste DV. Prevalence of and risk factors for medication nonadherence in patients with schizophrenia: a comprehensive review of recent literature. $J$ Clin Psychiatry. 2002;63:892-909.

6. American Psychiatric Association. Practice guideline for the treatment of patients with schizophrenia. 2nd ed. Arlington: American Psychiatric Association; 2004.

7. Kane JM, Leucht S, Carpenter D, Docherty JP; for Expert Consensus Panel for Optimizing Pharmacologic Treatment of Psychiatric Disorders. The expert consensus guideline series. Optimizing pharmacologic treatment of psychotic disorders. Introduction: methods, commentary, and summary. J Clin Psychiatry. 2003;64 Suppl 12:S5-S19.

8. Lehman AF, Kreyenbuhl J, Buchanan RW, et al. The Schizophrenia Patient Outcomes Research Team (PORT): updated treatment recommendations 2003. Schizophr Bull. 2004;30:193-217.

9. National Institute for Health and Clinical Excellence. Schizophrenia. Core interventions in the treatment and management of schizophrenia in primary and secondary care (update). 2009.
10. RANZCP. Royal Australian and New Zealand College of Psychiatrists clinical practice guidelines for the treatment of schizophrenia and related disorders. Aust N Z J Psychiatry. 2005;39:1-30.

11. Haro JM, Edgell ET, Frewer P, Alonso J, Jones PB; for SOHO Study Group. The European Schizophrenia Outpatient Health Outcomes Study: baseline findings across country and treatment. Acta Psychiatr Scand Suppl. 2003;7-15.

12. Sim K, Su A, Ungvari GS, et al. Depot antipsychotic use in schizophrenia: an East Asian perspective. Hum Psychopharmacol. 2004;19:103-109.

13. Karagianis J, Novick D, Pecenak J, et al. Worldwide-Schizophrenia Outpatient Health Outcomes (W-SOHO): baseline characteristics of pan-regional observational data from more than 17,000 patients. Int $J$ Clin Pract. 2009;63:1578-1588.

14. Stroup TS, Lieberman JA, McEvoy JP, et al. Results of phase 3 of the CATIE schizophrenia trial. Schizophr Res. 2009;107:1-12.

15. Price N, Glazer W, Morgenstern H. Demographic predictors of the use of injectable versus oral antipsychotic medications in outpatients. $\mathrm{Am}$ J Psychiatry. 1985;142:1491-1492.

16. Shi L, Ascher-Svanum H, Zhu B, Faries D, Montgomery W, Marder SR. Characteristics and use patterns of patients taking first-generation depot antipsychotics or oral antipsychotics for schizophrenia. Psychiatr Serv. 2007;58:482-288.

17. Valenstein M, Copeland LA, Owen R, Blow FC, Visnic S. Adherence assessments and the use of depot antipsychotics in patients with schizophrenia. J Clin Psychiatry. 2001;62:545-551.

18. Vehof J, Postma MJ, Bruggeman R, et al. Predictors for starting depot administration of risperidone in chronic users of antipsychotics. $J$ Clin Psychopharmacol. 2008;28:625-630.

19. American Psychiatric Association (APA). Diagnostic and Statistical Manual of Mental Disorders (DSM-IV). Washington DC: American Psychiatric Association; 1994.

20. Guy W. ECDEU assessment manual for psychopharmacology. Rockville, MD: US Department of Health, Education, and Welfare, Public Health Service, Alcohol, Drug Abuse, and Mental Health Administration, National Institute of Mental Health, Psychopharmacology Research Branch, Division of Extramural Research Programs; 1976.

21. Amador XF, Strauss DH, Yale SA, Gorman JM. Awareness of illness in schizophrenia. Schizophr Bull. 1991;17:113-132.

22. Hogan TP, Awad AG, Eastwood R. A self-report scale predictive of drug compliance in schizophrenics: reliability and discriminative validity. Psychol Med. 1983;13:177-183.

23. The EuroQol Group. EuroQol - a new facility for the measurement of health-related quality of life. Health Policy. 1990;16:199-208.

24. Ware JE Jr, Sherbourne CD. The MOS 36-item short-form health survey (SF-36). I. Conceptual framework and item selection. Med Care. 1992;30:473-483.

25. Dolan P. Modeling valuations for EuroQol health states. Med Care. 1997;35:1095-1108.

26. Cohen, J. Statistical Power Analysis for the Behavioral Sciences. 1 st ed. New York: Academic Press; 1969

27. Heres S, Hamann J, Mendel R, et al. Identifying the profile of optimal candidates for antipsychotic depot therapy A cluster analysis. Prog Neuropsychopharmacol Biol Psychiatry. 2008;32:1987-1993.

28. Remington G, Kwon J, Collins A, Laporte D, Mann S, Christensen B. The use of electronic monitoring (MEMS) to evaluate antipsychotic compliance in outpatients with schizophrenia. Schizophr Res. 2007;90: 229-237.

29. Ascher-Svanum H, Zhu B, Faries D, Lacro JP, Dolder CR. A prospective study of risk factors for nonadherence with antipsychotic medication in the treatment of schizophrenia. J Clin Psychiatry. 2006;67: 1114-1123.

30. Weiden PJ, Kozma C, Grogg A, Locklear J. Partial compliance and risk of rehospitalization among California Medicaid patients with schizophrenia. Psychiatr Serv. 2004;55:886-891.

31. West JC, Marcus SC, Wilk J, Countis LM, Regier DA, Olfson M. Use of depot antipsychotic medications for medication nonadherence in schizophrenia. Schizophr Bull. 2008;34:995-1001. 
32. Olfson M, Marcus SC, Ascher-Svanum H. Treatment of schizophrenia with long-acting fluphenazine, haloperidol, or risperidone. Schizophr Bull. 2007;33:1379-1387.

33. Bitter I, Treuer T, Dyachkova Y, Martenyi F, McBride M, Ungvari GS. Antipsychotic prescription patterns in outpatient settings: 24-month results from the Intercontinental Schizophrenia Outpatient Health Outcomes (IC-SOHO) study. Eur Neuropsychopharmacol. 2008; 18:170-180.

34. Chong MY, Tan CH, Fujii S, et al. Antipsychotic drug prescription for schizophrenia in East Asia: rationale for change. Psychiatry Clin Neurosci. 2004;58:61-67.

35. Yang YK, Tarn YH, Wang TY, et al. Pharmacoeconomic evaluation of schizophrenia in Taiwan: model comparison of long-acting risperidone versus olanzapine versus depot haloperidol based on estimated costs. Psychiatry Clin Neurosci. 2005;59:385-394.

36. Shinfuku N, Tan CH. Pharmacotherapy for schizophrenic inpatients in East Asia - changes and challenges. Int Rev Psychiatry. 2008;20: 460-468.

37. Swartz MS, Wagner HR, Swanson JW, et al. The effectiveness of antipsychotic medications in patients who use or avoid illicit substances: results from the CATIE study. Schizophr Res. 2008;100:39-52.

38. Heres S, Schmitz FS, Leucht S, Pajonk FG. The attitude of patients towards antipsychotic depot treatment. Int Clin Psychopharmacol.2007; $22: 275-282$
39. Patel MX, de Zoysa N, Bernadt M, David AS. A cross-sectional study of patients' perspectives on adherence to antipsychotic medication: depot versus oral. J Clin Psychiatry. 2008;69:1548-1556.

40. Taylor DM, Young CL, Mace S, Patel MX. Early clinical experience with risperidone long-acting injection: a prospective, 6-month follow-up of 100 patients. J Clin Psychiatry. 2004;65:1076-1083.

41. Heres S, Hamann J, Kissling W, Leucht S. Attitudes of psychiatrists toward antipsychotic depot medication. J Clin Psychiatry. 2006; 67:1948-1953.

42. Patel MX, de Zoysa N, Baker D, David AS. Antipsychotic depot medication and attitudes of community psychiatric nurses. J Psychiatr Ment Health Nurs. 2005;12:237-244.

43. Patel MX, Nikolaou V, David AS. Psychiatrists' attitudes to maintenance medication for patients with schizophrenia. Psychol Med. 2003; 33:83-89.

44. Perkins DO. Predictors of noncompliance in patients with schizophrenia. J Clin Psychiatry. 2002;63:1121-1128.

45. Fenton WS, Blyler CR, Heinssen RK. Determinants of medication compliance in schizophrenia: empirical and clinical findings. Schizophr Bull. 1997;23:637-651.
Patient Preference and Adherence

\section{Publish your work in this journal}

Patient Preference and Adherence is an international, peer-reviewed, open access journal that focusing on the growing importance of patient preference and adherence throughout the therapeutic continuum. Patient satisfaction, acceptability, quality of life, compliance, persistence and their role in developing new therapeutic modalities and compounds to

\section{Dovepress}

optimize clinical outcomes for existing disease states are major areas of interest. This journal has been accepted for indexing on PubMed Central. The manuscript management system is completely online and includes a very quick and fair peer-review system. Visit http://www.dovepress.com/ testimonials.php to read real quotes from published authors. 